\title{
Nostalgia, Memória e Mediação Sociocultural: Desvendando a Importância da Memória Televisiva por meio das Telenovelas Veiculadas no Canal Viva ${ }^{1}$
}

\author{
Nostalgia, Memory and Cultural Mediation: Unraveling the Importance of Television Memory \\ from the Soap Opera on Channel Viva
}

\begin{abstract}
La Nostalgia, La Memoria y Mediación Cultural: Desentrañar la Importancia de la Televisión de Difusión de las Telenovelas en el Canal Viva
\end{abstract}

Priscila CHÉQUER ${ }^{2}$

FERNANDES, Júlio Cesar. A memória televisiva como produto cultural: um estudo de caso das telenovelas do Canal Viva. Jundiaí, SP: Editora In House, 2014. 194 p. ISBN 978-85-7899298-9.

"A memória televisiva como produto cultural", publicado recentemente pela Editora In House, é o resultado da pesquisa de mestrado que Júlio César Fernandes defendeu no Programa de Pós-Graduação Multidisciplinar em Comunicação Social, da Universidade Metodista de São Paulo (UMESP). Parte integrante da coleção Pró-TV ${ }^{3}$, o livro tem por objetivo realizar um estudo sobre o resgate da memória televisiva por meio das telenovelas do acervo da Rede Globo que são veiculadas diariamente no Canal Viva. Para isso, o autor lança mão de uma base bibliográfica capaz de dar conta dos conceitos-chave de desenvolvimento do trabalho, como cultura, memória, identidade e recepção televisiva. Soma-se ao embasamento teórico o extenso trabalho de campo que incluiu pesquisa e análise documental na base de dados do Canal Viva e um Estudo de Recepção, baseado em autores como Jesus Martín-Barbero e Guillermo Orozco, que compreendeu a criação de um grupo focal com telespectadores assíduos do Canal. Partindo da hipótese de que a memória televisiva é importante na construção da memória coletiva e individual, sendo, portanto, um elemento ativo na trama das mediações, Fernandes defende que o resgate televisivo "torna possível que indivíduos e grupos sociais sejam estimulados a revisitar o passado no presente e discutir esse mesmo presente, por meio de narrativas do passado" (p. 22).

O primeiro capítulo, intitulado "A TV no Brasil e a memória televisiva”, apresenta-nos

1 Resenha apresentada à oitava edição da Revista Ação Midiática - Estudos em Comunicação, Sociedade e Cultura, publicação ligada ao Programa de Pós-Graduação em Comunicação, da Universidade Federal do Paraná.

2 Mestranda no Programa Multidisciplinar de Pós-Graduação em Cultura e Sociedade na Universidade Federal da Bahia, Salvador. Graduada em Comunicação Social com habilitação em Rádio e TV pela Universidade Estadual de Santa Cruz (UESC), Ilhéus, BA. Email: priscilachequer@gmail.com.

3 Associação dos Pioneiros da Televisão, entidade sem fins lucrativos que se dedica à conservação histórica da memória televisiva. Em parceria com a Editora In House lançaram um selo próprio (Coleção Pró-TV) para publicação de obras voltadas para a comunicação nacional. 


\section{açã(g) Midiática \\ № 8 । Ano 2014}

uma bem-sucedida retrospectiva histórica da TV brasileira dividida em cinco décadas do século XX - 1950, 1960, 1970, 1980, 1990 - e o século XXI. Por meio desse resgate podemos revisitar o percurso da televisão no Brasil desde a sua implantação até os dias atuais, perpassando fatos, acontecimentos e programas que marcaram época e atingiram picos de audiência pela sua temática, inovação técnica e/ou estética. Revisitamos o surgimento e o declínio de emissoras consagradas, como a TV Tupi, a TV Excelsior e a TV Manchete, além de embarcarmos em uma história bem construída que nos conta os caminhos e os percursos percorridos pelas demais emissoras em uma corrida em busca da consolidação no mercado das comunicações.

A telenovela tem especial destaque no subtítulo "Novela, cultura e identidade", em que o autor a defende como um dos principais produtos da televisão brasileira, destacando sua evolução histórica - transformação dos folhetins franceses e das radionovelas cubanas para as produções atuais - e sua importância econômica para emissoras, com a implantação do padrão de qualidade, da estrutura de produção dos centros de gravações, da parceria bem-sucedida com a indústria fonográfica, entre outros. Ao final do capítulo é perceptível que a temática da memória televisiva é um assunto caro ao autor e que, por isso, há um esmero e uma dedicação nessa reconstrução histórica, realizada não só por meio de relatos textuais, mas também pela quantidade de fotografias organizadas de forma a ilustrar o momento retratado.

No segundo capítulo, "Memória, identidade e cultura", o embasamento teórico do tema propõe um estudo apurado sobre o conceito de memória e sua interligação com as ideias de identidade e cultura. Conceito-chave para o desenvolvimento do trabalho, a noção de memória é discutida com base nas ideias do teórico Maurice Halbwacks, para quem as memórias individuais e coletivas estão interligadas no imaginário de um mesmo indivíduo que dialoga sua memória individual - lembranças de seus momentos vividos - com a memória coletiva do grupo ou grupos sociais onde está inserido. Dessa maneira, apropriamo-nos dessa memória coletiva para rememorar o passado, apegando-nos afetivamente a lembranças que originalmente não são nossas, mas que fazem parte do imaginário coletivo social. Nessa perspectiva, o autor defende que a memória televisiva - resgatada, nesse caso específico, por meio das telenovelas do Canal Viva - contribui para a construção do ideal de nação presente no imaginário nacional e "principalmente no estudo da construção de identidades coletivas. Para a criação e a afirmação de identidades culturais nacionais, é crucial que haja a preservação de sua história" (p. 95). Fernandes marca seu posicionamento teórico pela lógica dos Estudos Culturais citando autores como Stuart Hall - para fundamentar o entendimento das identidades no indivíduo pós-moderno e a ampliação do conceito de cultura para todas as práticas sociais humanas, incluindo a produção cultural e os meios de comunicação - e Jesus Martín-Barbero para compreender a problemática das mediações no Estudo de Recepção. Nesse ponto, o autor questiona se a memória televisiva pode ser inserida no mapa das mediações 


\section{açã(g) Midiática \\ № 8 I Ano 2014}

socioculturais e de que maneira ela interfere na recepção de telenovelas antigas pelo sentimento de nostalgia.

Essa hipótese será confirmada no terceiro capítulo, "O canal Viva e a memória televisiva na trama das mediações e interações socioculturais". Para chegar aos resultados apresentados, e à pesquisa em si, o autor elaborou um Estudo de Caso em três etapas: visita ao Canal Viva com o estudo de documentos institucionais (portfólios comerciais, guias de programação, etc.), entrevista com profissionais do canal e por fim a criação de um grupo focal com telespectadores assíduos da emissora. O estudo na base de dados do Viva e a entrevista com seus funcionários revelou detalhes de seus acordos comerciais com a Rede Globo, perfil de público, dados de audiência, estratégias de aproximação com os telespectadores, prioridades comerciais na escolha da grade de programação, dentre outras informações detalhadas que nos ajudam a entender a lógica de funcionamento da emissora, sua relação com o público e especialmente com a Rede Globo, principal fornecedora dos programas veiculados.

A entrevista mediada com o grupo focal destaca a interação dos telespectadores das telenovelas do Canal por meio das categorias de mediação propostas por Orozco: institucional (família, religião, etc.), videotecnológica (TV com sua linguagem, áudio e imagem), situacional (onde e com quem se assiste à programação televisiva), referência (idade, sexo, classe social, etc.) e cognitiva (repertório pessoal do telespectador). Cada uma dessas mediações interfere de algum modo na recepção televisiva, porém, fica claro, nos resultados obtidos, o lugar de destaque da mediação cognitiva tendo o sentimento de nostalgia como um dos principais impulsionadores para a audiência das telenovelas reprisadas no Canal Viva. Inúmeros entrevistados relataram na discussão do grupo focal reviver, por meio das novelas assistidas, momentos específicos de suas vidas, como lembranças de infância, interação com familiares e até mesmo aspectos políticos e sociais do país. Com base nessas informações, percebemos o importante papel desempenhado pelas telenovelas na conservação da memória afetiva e individual, coletiva e nacional.

De modo geral, os objetivos inicialmente propostos por Fernandes são cumpridos à medida que, por meio de uma revisão histórica, bibliográfica e do Estudo de Caso, o autor consegue provar a importância da memória televisiva na construção da memória coletiva, individual e nacional. Pensar sua temática à luz dos Estudos Culturais afasta seu trabalho da tendência acadêmica dos anos 70 e 80 no Brasil, que resistia em considerar a telenovela uma possibilidade de estudo dentro do campo cultural. Pesavam sobre ela sua produção industrial, seu caráter de entretenimento, sua origem melodramática dos folhetins, entre outros fatores que, de acordo com Sílvia Borelli, alimentavam, em certa medida, um "preconceito acadêmico". O paradoxo que anteriormente afastava os pesquisadores por não conseguirem apreender seu caráter híbrido, mestiço e sua inadequação aos critérios de classificação, como culto ou erudito, ganha espaço com a emergência dos Estudos Culturais, que ampliaram o conceito de cultura e 
trouxeram para o campo acadêmico um novo debate sobre os meios de comunicação de massa. Fernandes refaz esse caminho ao trazer para seu texto o diálogo entre teóricos como Zigmunt Bauman, Theodor Adorno, Stuart Hall, Jesus Martín-Barbero, Nestór Canclini, entre outros, que nos ajudam a refletir sobre as lógicas e as produções culturais na pós-modernidade.

Por fim, a leitura desse livro nos desperta para a problemática atual de preservação da memória televisiva. Ao observarmos casos bem-sucedidos de institutos de conservação e disponibilização ao público do material audiovisual, como os da Argentina, da Inglaterra, da França e dos Estados Unidos, relatados por Fernandes, percebemos como o Brasil - maior produtor de telenovelas do mundo - está aquém no que diz respeito à conservação desse material. Registro vivo da história nacional, a memória televisiva tem um papel fundamental no resgate histórico de uma nação, nesse sentido, iniciativas que visem a proteger, conservar e disponibilizar esses arquivos deveriam ser ações das instituições públicas. Fora isso, cabe a algumas iniciativas privadas, como a da Pro-TV, e à academia o papel de contribuir com o resgate da memória televisiva. Nesse sentido, a obra aqui analisada obteve êxito ao nos apresentar essa temática e contribuir para os futuros trabalhos acadêmicos que visem ao estudo e à recuperação de nossa história mediada pelos meios de comunicação de massa. 